\title{
Contribuições da história indígena da Paraíba para uma ética de preservação ambiental
}

\author{
Raquel de Lourdes de Miranda e Silva Carmona ${ }^{1}$, Cassiano \\ Augusto Oliveira da Silva ${ }^{1}$, Carlos André Macêdo Cavalcanti ${ }^{1}$, João \\ Carlos de Miranda e Silva ${ }^{2}$, Cícero Sousa Lacerda ${ }^{3}$, Érika Marques \\ de Almeida Lima ${ }^{3}$, Josemary M. Freire Rodrigues de C. Rocha ${ }^{3}$, \\ Patrícia Tavares de Lima $^{3}$, Hercílio de Medeiros Sousa ${ }^{3}$, Luciano \\ Honório de Carvalho $^{3}$ e Natália Marques de Almeida Lima \\ Miranda $^{4}$
}

${ }^{1}$ Universidade Federal da Paraíba. Programa de Pós-Graduação em Ciências das Religiões. Centro de Educação. Universidade Federal da Paraíba. Campus I. João Pessoa-PB, Brasil. (CEP 58051-900) E-mail: carmona.miranda@gmail.com.

${ }^{2}$ Superintendência de Administração de Meio Ambiente - SUDEMA. Av. Monsenhor Walfredo Leal, 181. Tambiá. João Pessoa-PB, Brasil (CEP 58020-540).

${ }^{3}$ Instituto de Ensino Superior da Paraíba - IESP. Estrada de Cabedelo. BR 230, km 14, s/n. Morada Nova. Cabedelo-PB, Brasil (CEP 58109-303).

${ }^{4}$ Instituto do Patrimônio Histórico e Artístico da Paraíba. Av. João Machado, 348. Jaguaribe. João Pessoa-PB, Brasil (CEP 58013-520).

Resumo. Este artigo vem se somar ao entendimento de que é necessária uma reflexão mais apurada acerca do papel das reservas indígenas paraibanas, no sentido do seu contingente populacional que preserva, ainda que de maneira muito restrita os saberes tradicionais, trazendo assim, uma sensível contribuição para uma fundamental ética de preservação ambiental. Trata-se de um breve estudo que vai apresentar um panorama histórico e um olhar antropológico acerca do aspecto preservacionista do patrimônio natural presente no litoral paraibano, nomeadamente nas terras indígenas Tabajara, no litoral sul da Paraíba que vem se consolidando como espaço de ressignificação para um povo que enfrenta cotidianamente os desafios de preservar um legado ancestral, corroborando com a preservação ambiental.

Palavras-chave: Ética de preservação ambiental; História da Paraíba; Povo Tabajara.

Abstract. Contributions from Paraíba's indigenous history to an ethic of environmental preservation. This article is an addition to the understanding that a closer reflection is needed about the role of Paraíba's indigenous reserves, in the sense of their population contingent that preserves, although in a very restricted way, the folk knowledge, thus bringing a significant contribution to a fundamental ethics of environmental

Recebido:

$21 / 07 / 2019$

Aceito:

$30 / 08 / 2019$

Disponível on line: $31 / 08 / 2019$

Publicado: $31 / 08 / 2019$

Acesso aberto

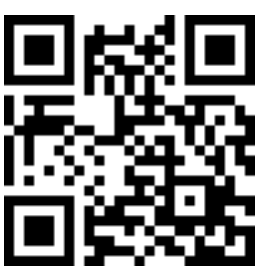

ORCID

(1) 0000-0002-7192-3297 Raquel de Lourdes de Miranda e Silva Carmona 
preservation. What follow is a brief study that will present a historical panorama and an anthropological look about the preservationist aspect of the natural heritage present in the Paraíba coast, namely in the Tabajara indigenous lands, in the south coast of Paraíba, which has been consolidating itself as a resignification space for a people who daily face the challenges of preserving an ancestral legacy, corroborating environmental preservation.

Keywords: Ethic of environmental preservation; History of Paraíba; Tabajara People.

\footnotetext{
(1) 0000-0002-8461-9104

Cassiano Augusto

Oliveira da Silva

(ㄱ) 0000-0003-0685-5803

Carlos André Macêdo

Cavalcanti

(D) 0000-0001-5979-6451

João Carlos de

Miranda e Silva

(1) 0000-0002-4047-5540

Cícero Sousa Lacerda

(1) 0000-0003-0630-7057
Érika Marques de
Almeida Lima

(ㄱ) 0000-0002-3267-4670

Josemary M. Freire

Rodrigues de C. Rocha

(1) 0000-0002-4361-7196

Patrícia Tavares de

Lima

(1) 0000-0002-7209-0995

Hercílio de Medeiros

Sousa

(1) 0000-0002-2896-427X

Luciano Honório de

Carvalho

(1) 0000-0002-0037-8965

Natália Marques de

Almeida Lima Miranda
}

\section{Introdução}

0 presente trabalho vem refletir sobre o atual contexto socioambiental no qual se encontra a humanidade e esta está diretamente relacionada a práticas sociais que refletem no meio natural pela degradação permanente do meio ambiente e do seu ecossistema. Refletir sobre meio ambiente é muito mais do que apenas trabalhar com noções da ecologia ou das ciências biológicas é um articular de produção de sentidos que envolve diretamente uma ética de preservação do meio ambiente. Atores diversos estão envolvidos nesta temática e a educação vem como um instrumento de fundamental importância para potencializar o engajamento dos diversos sistemas de conhecimento, a capacitação de profissionais e a comunidade científica numa perspectiva de interdisciplinaridade com 0 meio ambiente e seus recursos.

Adentrando na seara das relações entre o meio natural e o social, vimos conjeturar um pouco a respeito da história dos povos indígenas da Paraíba, os Tabajaras e Potiguaras, onde lutando por suas terras e com ela interagindo, a ética de preservação se faz algo palpável, concreto e de resultados que vai além do discurso, mas que chega e reverbera como elemento essencial na identidade de um povo.

É fato que não podemos comparar uma aldeia indígena com uma cidade, no sentido de equalizar o ritmo de vida, que é totalmente diferente. Mas ambicionamos, a partir de uma realidade, fomentar como a organização social é capaz de aumentar o poder de ações 
alternativas na tentativa de se construir uma ética ambiental numa perspectiva que priorize novo perfil de desenvolvimento, com ênfase na sustentabilidade socioambiental. É necessário, portanto, a quebra de atuais paradigmas que apenas fortalece a crescente degradação das condições de vida, também é preciso refletir sobre os novos desafios a serem transpostos com foco na mitigação da crise ambiental que assola o mundo.

Assim, este artigo vem instigar a reflexão sobre os problemas ambientais, trazendo um pouco de como o povo indígena em particular da Paraíba com sua história de luta e resistência, no seu jeito singular de ser pode se fazer exemplo para a construção de uma ética ambiental também fora daquela realidade aldeã, mas extremamente evoluída no quesito educação ambiental e vida.

\section{Meio ambiente e seus recursos - transformações e consciência}

A cadência pela qual ocorre o progresso técnico-científico se dá de forma muito mais rápida do que a reflexão de cunho ético e, isto se dá pelo mal-estar difuso pelo qual vem passando as civilizações, figuram o descuido, 0 descaso e a falta de cuidado para com o próprio homem e com o meio que o cerca. 0 ser humano vem se comportando como se fora Deus e tem marcado a história com impiedade e insensatez (Boff, 1999, p. 18 e 21).

Nesta sociedade capitalista cunhada "do conhecimento", da rapidez da comunicação, muitas coisas tornam-se obsoletas, do dia para a noite, e certezas éticas de séculos passam a ser questionadas pelas inúmeras possibilidades emergentes, de forma contínua, diante dos novos cenários trazidos pela biotecnologia e pela tecnociência. Questionarmo-nos a respeito do que deveria permanecer e mudar? Que deveria e seria saudável alterar? São questões difíceis, que exige bastante aprendizado referente ao diálogo, de espírito de tolerância e de respeito ao diferente. Teremos de, forçosamente, alcançar consensos mínimos em relação a questões essenciais de proteção da vida humana e daquilo que é imprescindível para a sua manutenção na Terra, como o meio ambiente e os recursos naturais. Sendo necessária uma ética, faz-se necessário uma ética ambiental, até por que a problemática do meio-ambiente é também um problema moral (Pessini, 2007, p. 40-45).

Esta ética preocupa-se com a conduta dos indivíduos responsáveis com respeito a paisagens naturais, recursos, espécies e organismos nãohumanos. 0 modo próprio de agir dos seres humanos é preocupação direta da filosofia moral como tal. A Ética, no sentido exato, "ambiental" vem incluir em seu escopo, perguntas referentes às peculiaridades do meio-ambiente, buscando responder à problemática de como preservá-lo, a fim de garantir o futuro da humanidade (Silva, 2010, p. 135).

Agir para o provimento de um ecossistema sustentável, ação que se configura como meta do movimento ambiental, envolve alguns princípios básicos, são eles: reciclagem dos elementos com o propósito de dispor racionalmente dos resíduos e promover a reposição dos nutrientes; uso de energia solar; colocação de limites à expansão das populações consumidoras e impedimentos ao excesso de pastagens; e a manutenção da biodiversidade. 0 estado de crise se desenvolve sempre que um desses princípios esteja comprometido (Nebel e Wright, 1993, p. 46).

Ao analisarmos as representações do meio natural no contexto social, podemos afirmar que o mundo contemporâneo vem se deparando com seríssimos problemas, decorrentes do processo de concepção de nossa sociedade, que foi erigida sem o conhecimento das leis que regem o meio 
natural e sem levar a sério as peculiaridades da essência do ser humano. Nenhuma espécie de ser vivo foi capaz de desenvolver-se ou de evoluir tanto como a espécie humana, mas tal evolução foi acompanhada, em passo igual, por um conturbado deslocamento, social, político, cultural e tecnológico (Pessini, 2007, p. 117).

Assim começam a surgir, a partir da década de 1960, tanto nos centros acadêmicos, das mais diversas áreas do conhecimento, como nas agências de governo, preocupações e discussões em torno do meio ambiente e dos temas ecológicos. Os anos 1970 é um referencial na questão ambiental, em 1972, aconteceu na cidade de Estocolmo, Suécia, a Conferência das Nações Unidas sobre a Humanidade, que é reconhecida como o primeiro encontro mundial sobre o tema ambiente humano. Nesta reunião havendo representantes de 113 países, inclusive do Brasil. As conclusões da Conferência da ONU sobre Ambiente Humano foram publicadas em um documento com dezenas de recomendações (Melo, 2002, p. 39).

Waine (1999) ressalta que em agosto de 1971, já se vinha discutindo no Brasil sobre essa questão, tendo ocorrido no Rio de Janeiro a VIII Reunião Internacional dos magistrados, onde se debateu a relação do jurista com o meio ambiente. Na Conferência de Estocolmo já havia se chegado à conclusão de que era preciso redefinir o próprio conceito de desenvolvimento, tantas e tão complexas eram as questões envolvidas (Novaes, 2003, p. 345).

Ainda no ano de 1972, um grupo de técnicos do Massachusetts Institute of Tecnology, sob o patrocínio do 'Clube de Roma', um grupo de empresários e intelectuais preocupados com o futuro da civilização, publicou o famoso relatório 'Limites do Crescimento', no qual se alinhavam inúmeros dados sobre o esgotamento de reservas minerais, aumento da população etc, no sentido de demonstrar a inviabilidade da continuação do atual modelo de crescimento industrial (Lago e Pádua, 2001, p. 33).

No que diz respeito à integração nessas discussões, na Conferência de Estocolmo, o Brasil participou como líder dos países subdesenvolvidos, e após essa participação podemos dizer que o país iniciou um processo de organização ambiental, criou-se então a Secretaria de Meio Ambiente (SEMA), assim como também começaram a surgir diversas Organizações Não Governamentais (ONG's) (Novaes, 2003, p. 323).

Por toda a década de 1980 os problemas ambientais continuaram e foram se radicalizando em todo o mundo. Em 1987, através de um relatório denominado Nosso Futuro Comum, o conceito de Desenvolvimento Sustentável se estabelece, como sendo aquele capaz de atender as necessidades das atuais gerações sem comprometer os direitos das futuras gerações (Novaes, 2003). Nesse momento o Brasil presentificava um acontecimento de importante relevância para sua história, que foi a elaboração da Constituição de 1988 (01/02/1987 a 05/10/1988), período considerado propício para a inclusão do meio ambiente como um tema (Wainer, 1999, p. 29).

Outro grande episódio desse caminhar em busca da proteção e do uso racional dos recursos ambientais, aconteceu no Rio de Janeiro, foi a "Conferência sobre Meio Ambiente e Desenvolvimento (Rio 92)". Conferência que trouxe consigo inúmeras recomendações e compromissos em relação a novos padrões éticos e comportamentais a serem adotados pelos governantes, empresas e coletividade em relação a preservação ambiental (Wainer, 1999, p. 37).

$\mathrm{Na}$ Rio 92, foi elaborado um documento intitulado "Agenda 21", que para Novaes. (2003, p. 326), não se trata, apenas, de um documento, mais sim de um processo de participação em que a sociedade, os governos, os setores econômicos e sociais sentam-se à mesa para diagnosticar os problemas, 
entender os conflitos envolvidos e pactuar formas de resolvê-los, de modo, a construir o que tem sido chamado de sustentabilidade ampliada e progressiva.

No decorrer dos anos 1980 e 1990, foram aprovadas, no Brasil inúmeras leis, como a Lei no 6.938/1981, que estabelece a Política Nacional do Meio Ambiente, a Lei no 7.735/1989 que cria o Instituto Brasileiro do Meio Ambiente e dos Recursos Naturais Renováveis (IBAMA), a Lei $\mathrm{n}^{\circ}$ $8.080 / 1990$, que vai dispor sobre as condições para a promoção, proteção e recuperação da saúde, a organização e o funcionamento dos serviços correspondentes e dá outras providências, a Lei no 9.605/1998, Lei de Crimes Ambientais, que tipifica os crimes nas ações lesivas ao meio ambiente e as respectivas penas, acrescentando a responsabilidade penal das pessoas jurídicas, a Lei no 9.795/1999, que estabelece a Política Nacional de Educação Ambiental, a Lei $\mathrm{n}^{\mathbf{o}}$ 9.782/1999, onde se define o Sistema Nacional de Vigilância Sanitária, cria a Agência Nacional de Vigilância Sanitária, e dá outras providências. Tantas outras leis subsequentes de mais variados temas foram sendo publicadas, tais como a Biossegurança em 2005, Saneamento Básico em 2007, Resíduos Sólidos em 2010, Código Florestal em 2012, etc.

A ação legal é importante, mas não é tudo, uma vez que a vulnerabilidade do meio ambiente continua a esbravejar seu estado de crise. Mas o que está faltando? Faz-se necessário um modo de agir positivo, individual e coletivo, precisamos de uma ética ambiental entre os povos. E quem melhor que os nativos de qualquer terra, neste caso em particular do Brasil, para nos ensinar sobre como se relacionar com o meio ambiente e seus recursos? 0 nativo possui um conhecimento acerca das questões ambientais locais totalmente integrado a sua vida, a dinâmica em prol de manutenção da sua vida é uma dinâmica intrínseca a manutenção do meio ambiente e de seus recursos naturais.

Se quisermos uma breve comprovação a respeito disto, basta um breve olhar para a história do nativo do Brasil, desde o início do processo de colonização até os dias atuais, estes são os brasileiros que conseguem viver harmonicamente com o meio natural garantindo a manutenção destes para esta e para as futuras gerações, estes retiram do meio natural apenas aquilo que necessitam basicamente para viver, com isto "a natureza vive seu tempo".

\section{0 indígena paraibano - posse da terra é manutenção da vida}

Um transcursar pela história do Brasil é um se aprofundar na luta de um povo por aquilo que é seu de direito, no caso a terra e, também na luta deste povo pela manutenção de um ambiente ecologicamente equilibrado, para que assim sejam capazes de se manterem vivos, estamos aqui tratando dos indígenas brasileiros. E que para Farias e Barcellos (2015, p. 92) os povos que no Brasil habitavam no período da vinda dos colonizadores para estas terras, viram sua terra e sua cultura invadida e vilipendiada pelos colonizadores europeus.

De acordo com o Instituto Brasileiro de Geografia e Estatística (IBGE, 2010) e do Instituto SócioAmbiental (ISA, 2016) os povos indígenas no Brasil chegam a totalizar quase 890.000 pessoas. Entretanto os mesmos não se encontram em organização perfeita e harmoniosa em relação ao Estado, uma vez que este compreende como indígenas somente aqueles localizados em terras tradicionalmente ocupadas por eles, de acordo com a Constituição Federal de 1988. Os conflitos agrários que marcam o país em meio a desastrosa política fundiária do Brasil é são alguns dos fatores que contribuíram e contribuem com a desintegração das populações indígenas, principalmente no nordeste 
brasileiro (Farias e Barcellos, 2015, p. 74).

No Estado da Paraíba, até recentemente, quando se falava em povos indígenas, éramos remetidos imediatamente ao Povo Potiguara. Estes estão localizados administrativamente entre os municípios de Baía da Traição, Rio Tinto e Marcação, região que corresponde a parte do litoral norte do Estado, entretanto outrora habitavam todo o vale do Mamanguape (Marques, 2009, p. 18; Farias e Barcellos, 2015, p. 22).

Os povos Tabajara tem como seu o território compreendido pelos Municípios do Conde, Alhada, Caaporã e Pitimbu. A história registrou lutas entre colonizadores e colonizados, a priori a relação com os colonizadores portugueses se deu de forma amistosa, mas depois conflitos foram descritos, principalmente com os Potiguaras. Os Potiguaras se mantiveram por muitas décadas numa força de resistência contra as constantes investidas pelo seu território. Já os Tabajaras devida a opressão sofrida recuaram a ponto de perder sua posição na história (Farias e Barcellos, 2015, p. 75 e 103).

De acordo com Farias e Barcellos (2015, p. 16-17), os indígenas aqui existentes, a partir do século XIX, entraram gradualmente num processo de dispersão e extinção. Com isto é criada a ideia do desaparecimento dos Cariris no sertão e dos Tabajaras no litoral sul. Ficando os Potiguaras figurando como os indígenas da Paraíba. Entretanto no remanejar comum a história, em 2006 o povo Tabajara se insere num processo de reorganização, reivindicando o reconhecimento de sua alteridade, recebendo auxilio de outros grupos e de agências engajadas com à causa indígena (Farias e Barcellos, 2015, p. 105).

A terra é direito dos povos indígenas e a luta por este bem acaba por inseri-lo num movimento de afirmação e reelaboração da identidade étnica. Para Keim e Santos (2013, p. 172) os povos indígenas são detentores de conheci- mentos e posturas, frente as questões ambientais. Assim, tal condicionante os constituem como pessoas que se orgulham de sua ancestralidade e se reconhecem como pertencentes a esse meio, ao meio natural, e que são os depositários de conhecimentos únicos e particulares, constituintes de sua cosmovisão, ou seja, de seu reconhecimento como ser no mundo e como ser que interage e que vive de forma integral em contato e numa relação de dependência com o meio ambiente e seus recursos.

0 processo de reorganização por qual o povo Tabajara tem vivido apresenta um caso de origem étnica (etnogênese) um grupo de pessoas descendentes dos Tabajaras dispersos na região do litoral sul formam um grupo étnico que vem assumir sua identidade e reivindicando seu reconhecimento oficial como indígena e como donos das terras dos antigos aldeamentos, dá-se início um processo de reconquista (Farias e Barcellos, 2015, p. 99-102).

Segundo Farias e Barcellos (2015, p. 132-134) praticamente o povo Tabajara sobrevive da pesca e da coleta de alguns frutos sazonais. A pesca é realizada nos rios e no mar, pescam peixe de portes diversos e camarões. A agricultura está diretamente ligada a subsistência, com o cultivo de cereais, algumas raízes, legumes, verduras e frutas. Entretanto, em período de safra, índios da aldeia Barra de Gramame aproveitam para arrecadar algum dinheiro com a venda de frutas à turistas a margem da rodovia PB-008. Além da criação de animais domésticos, patos, galinhas, porcos e bovinos. Já os que residem na periferia da grande João Pessoa acaba vivendo na informalidade em meio a baixa renda.

Os potiguaras possuem a "Mãe Terra" e as matas como locais sagrados. Estas fornecem toda a ornamentação das celebrações religiosas, são retirados troncos, galhos, raízes, cascas, folhas, flores, para a produção de remédios caseiros muito comuns na medicina 
tradicional indígena, a mata é rica em matéria prima de tantos sinais sacramentais. Aquela é lugar sagrado e apresenta os sinais vitais que são percebidos por aqueles que estão atentos, sendo capazes de escutar os segredos da natureza. A criação é algo divino. Não só os reinos animal e vegetal estão integrados nesse universo indígena, existe uma mitologia própria que adorna e dão sentido à vida dos indígenas (Barcellos, 2012, p. 106-121).

Por Barcellos (2012) a terra potiguara vem sofrendo a anos investidas danosas, sendo violentada por queimadas e desmatamentos e contaminada por agrotóxicos, pesticidas e herbicidas. Entretanto, a juventude potiguara vem se erguendo como uma resposta efetiva contra estas práticas mortíferas que se impõe a "Mãe Terra". Barcellos (2012, p. 113) traz-nos que "Um dos nossos deveres que eu acho essencial é proteger o meio ambiente, porque é dele que sai tudo que nós temos hoje ..." disse um jovem potiguara.

É bastante interessante a relação do indígena com a terra. 0 ser humano, nas várias culturas e fases históricas, revelou essa intuição segura: pertencemos à terra, somos filhos e filhas da terra, somos terra. Esta, entretanto não é algo diferente do homem, nós somos a própria terra que na sua evolução chegou ao estágio de sentimento, de compreensão, de vontade, de responsabilidade e de veneração. E conhecendo a história do universo e da terra, conheceremos a nós mesmos e a nossa ancestralidade (Boff, 1999, p. 72-73).

A transmissão pelos mais velhos, para o povo Tabajara, é a fonte do conhecimento sobre o meio ambiente e seus naturais. Aqueles vivenciaram e transmitem com seguridade uma intimidade com a agricultura, a pesca e a caça. 0 modo como seus ancestrais viveram instiga nos mais novos a gana de respeitar e crer nas entidades da natureza, como também a fazer o uso racional dos rios, dos mangues e dos recursos de mata atlântica (Farias e Barcellos, 2015, p. 133).

Lugares sagrados, mãe natureza, integração com os espíritos, animais gigantes, comadre florzinha (caapora ou caipora), são entes que integram a mitologia indígena e, como dissemos, dão sentido à vida do nativo. Os mitos, para Eliade (1972, p. 13), efetivamente, narram não apenas a origem do Mundo, dos seres (animal e vegetal) que nele interagem, mas também de todos os acontecimentos primordiais em consequência dos quais o homem se converteu até hoje. Se o mundo existe é porque os entes sobrenaturais desenvolveram uma atitude criadora do princípio.

Viver o saber da ancestralidade e crer nas entidades da natureza é manter vivo saberes e crenças: ambiental e espiritual. Assim nunca devemos esquecer que os portadores permanentes da espiritualidade são as pessoas consideradas comuns, que vivem a retidão da vida, o sentido da espiritualidade, e cultivam o espaço sagrado do Espírito, seja em suas religiões e igrejas, seja no modo como pensam, agem e interpretam a vida, a exemplo do povo Tabajara (Boff, 2001, p. 13).

\section{Ética ambiental é uma espiritualidade em prol da vida}

A contemporaneidade vem sendo construída e fortemente marcada por suas formações sociais implementadas pelo processo de industrialização capitalista, onde o modo de produção e a relações sociais se autolegitimam. Acentua-se a isto a implementação pelo capital transnacional, pela mundialização e pela velocidade de informações, que escancara um panorama geral de rápidas mudanças econômicas, sociais e políticas, resultando num caos socioambiental (Vilhena, 2005, p. 47).

Segundo Boff (2001, p. 10-11) a espiritualidade, neste caos socioambiental, assolado pelos mitos de 
exterminação da espécie, da liquidificação da biosfera, da ameaça do futuro comum da Terra e da humanidade, configura-se como uma das fontes de primeiras de inspiração do novo, de esperança alvissareira de geração de um sentido pleno e de capacidade de auto transcendência do ser humano.

E esta nova fonte de inspiração não se configura como um elemento confinado a seu lugar em especifico, as religiões, mas hoje tem adentrado em âmbitos os discursos são os mais contrários no que se refere a religiosidade. Executivos internacionais, grupos de empresários, jovens e tantos outros, discutindo sobre mudanças sociais, novo paradigma civilizatório, produtividade da nova tecnologia robótica e inserido a isto, a espiritualidade humana. Ou seja, existe um vazio no íntimo do ser humano que precisa ser preenchido e que este preenchimento seja capaz de gerar mudanças - no modo de pensar, no modo de agir e no modo de como nós humanos enfrentamos a vida (Boff, 2001, p. 11-13).

A interioridade humana é composta de muitos centros energéticos e por diferentes fontes de sentido. É justamente por isto que somos tidos por seres espirituais além de corporais e psíquicos. 0 homem possui muitos centros vitais - a razão, o poder, o desejo, o coração, mas não somos dominados por eles, somos perpassados e circundados por muitos - dinamismo e dramaticidade - eles fazem a vida humana. E quando articulados na existência única de cada pessoa, através de cada uma destas energias, temos acesso à Energia suprema que habita o universo e o coração humano (Boff, 1999, p. 38).

Atitudes como compaixão, paciência, tolerância, capacidade de perdoar, contentamento, noção de responsabilidade e a noção de harmonia, tudo isto capaz de trazer felicidade tanto para a própria pessoa quanto para o coletivo, são características da espiritualidade. Espiritualidade não é religião, é tudo aquilo que possui a capacidade de produzir mudanças interiores no ser humano e, o objetivo da prática espiritual é, consequentemente, a da prática ética é transformar e aperfeiçoar o estado geral do coração e da mente (Boff, 2001, p. 16-25).

0 homem, não me refiro ao fiel religioso, mas aquele que carrega a identidade da espiritualidade, interage com o mundo que o cerca numa prática profundamente coerente, numa amorosidade com os outros, numa compaixão com os que sofrem, num sentido de responsabilidade com os seus semelhantes e numa vida de um despojamento que nos deixa aberto para acolher tudo o que vier da realidade (Boff, 2001, p. 24-25).

Segundo Boff (1999, p. 38-39) é no cuidado que iremos encontrar o ethos (conjunto de valores, princípios e inspirações que dão origem a atos e atitudes - as várias morais) necessário para a sociabilidade humana e principalmente para identificar a essência fontal do ser humano, homem e mulher e, que conformação o habitat comum e a nova sociedade que nasce. Diante do caos social e ambiental em que vivemos, emerge a necessidade de um novo ethos de cuidado, de sinergia, de paz perene para com a Terra e para com a vida.

Vilhena (2005, p. 53) ressalta que somos povos de vários povos, somos uma nação que se caracteriza pela pluralidade, pelo hibridismo, pela mestiçagem e, pela composição com outras subculturas de cosmovisões diversas nas quais se localizam antropologias e compreensões diversas de mundo e de tantos outros conceitos e valores. Assim, quando nos referimos a um ethos não estamos postulando a respeito da determinação de padrões, mas de objetivos comuns para a preservação da espécie humana por meio da preservação do meio ambiente e dos recursos naturais. 
Refletindo sobre a ponderação de preservação da natureza e, por conseguinte do homem na Terra e, correlacionando como a forma que vivem nossos nativos, em particular os Tabajaras e Potiguaras, é visível por ser concreto a existência de uma ética ambiental tradicional indígena direcionada ao uso sustentável do meio ambiente e dos recursos da natureza. Uso sustentável que reconhece o ser humano não como o centro, mas como apenas mais uma parte integrante da natureza, com a qual se relaciona de forma racional, igualitária e respeitosa, muito diferente daquilo que expusemos anteriormente sobre a sociedade contemporânea, onde nesta o ser humano se considera proprietário dos recursos naturais, numa relação hierárquica onde sua suposta "superioridade natural" lhe possibilita a utilização dos recursos da natureza benefício próprio.

\section{Considerações finais}

No decorrer deste trabalho vimos que o mundo vem sendo assolado por investidas danosas contra o ser humano e o meio ambiente e a atual conjuntura vem exigindo novas posturas sociais diante dos diversos problemas sócios ambientais que faz com que o plante agonize e o povo, por conseguinte padeça mais e mais.

A problemática socioambiental, ao questionar ideologias teóricas e práticas, propõe a participação democrática da sociedade com caráter multissetorial capaz de aditar inúmeras tendências orientadoras de ações ambientalistas na gestão dos seus recursos atuais e potenciais, assim como no processo de tomada de decisões para a escolha de novos estilos de vida e a construção de um futuro possível, sob a ótica da sustentabilidade ecológica e a equidade social - justiça, cidadania, democracia e conservação ambiental.
Diante desta realidade, vimos relatar a diligência dos povos indígenas da Paraíba, Tabajaras e Potiguaras que no processo de reconquista e manutenção da terra, mesmo não sendo ecologistas por natureza, isto levando em consideração a essência do termo, reconhecendo os créditos históricos de um povo que, assim como os demais indígenas do Brasil, manejam a terra e fazem uso dos recursos naturais e do meio ambiente de forma racional, onde partindo do caráter místico de sua relação com o meio ambiente e seus recursos, foram capazes de construírem e viverem uma ética de preservação no meio natural em que interagem, desde antes de existir nos livros a terra Brasil.

Nosso primeiros habitantes e donos das terras brasileiras são os exemplos mais concreto de manutenção estável da relação entre o meio ambiente e o homem, não estou aqui postulando um padrão de vida nativo, mas postulo a necessidade de se refletir a forma como utilizamos o meio ambiente e seus recursos e como poderíamos numa relação racional estável, estabelecer uma ética de preservação ambiental, mesmo fazendo uso dos recursos do meio ambiente e da natureza, uma vez que este também é indispensável para a manutenção da vida humana.

\section{Conflito de interesses}

Os autores declaram não haver conflitos de interesses.

\section{Referências}

Barbosa, A. C. A. Educação da criança na revitalização da identidade indígena: 0 contexto xokleng/laklãnõ. Blumenau: Universidade Regional de Blumenau, 2011. (Dissertação de mestrado).

Barcellos, L. Práticas educativo-religiosas dos Potiguaras da Paraíba. João Pessoa: UFPB, 2012. 
Boff, L. Espiritualidade: um caminho de transformação. Rio de Janeiro: Sextante, 2001.

Boff, L. Saber cuidar: ético do humano compaixão pela Terra. 10. ed. Petrópolis: Vozes, 2004.

Brasil. Agenda 21 - Conferência das nações unidas sobre meio ambiente e desenvolvimento. 3. ed. Brasília: Senado Federal, 2001.

Eliade, M. Mito e realidade. São Paulo: Perspectiva, 1972.

Farias, E.; Barcellos, L. Memória Tabajara: manifestações de fé e identidade étnica. 2. ed. João Pessoa: UFPB, 2015.

IBGE - Instituto Brasileiro de Geografia e Estatística. Dados do Censo 2010. Disponível em: <http://www.ibge.gov.br>. Acesso em: 21 fev. 2019

ISA - Instituto Sócio-Ambiental. Povos indígenas no Brasil. Disponível em: $<$ https://www.socioambiental.org/ptbr/oisa/programas/povos-indigenas-nobrasil>. Acesso em: 21 jan. 2019.

Keim, E. J.; Santos, F. Educação escolar indígena: interculturalidade e cosmovisão na revitalização da língua e cultura Xokleng/Laklãnõ. Revista Teoria e Prática da Educação, v. 16, n. 2, p. 169-183, 2013.

Lago, A.; Pádua, J. A. 0 que é Ecologia. São Paulo: Brasiliense, 2001. (Coleção Primeiro Passo, 116).
Liebmann, H. Terra um planeta inabitável? Da antiguidade até os nossos dias, toda a trajetória poluidora da humanidade. Rio de Janeiro: Biblioteca do Exército, 1979.

Marques, A. C. N. Território de memória e territorialidades da vitória dos Potiguara da Aldeia Três Rios. João Pessoa: UFPB, 2009. (Dissertação de mestrado).

Melo, G. P. Noções práticas de educação ambiental para professores e outros agentes multiplicadores. João Pessoa: GEREX/ IBAMA-PB, 2002.

Nebel, B. J.; Wright, R. T. Environmental Science: The way the world works. 4. ed. New York: Prentice Hall, 1993.

Novaes, W. Agenda 21. In: Trigueiro, A. (Org.). Meio ambiente no século 21. Rio de Janeiro: Sextante, 2003.

Pessini, L. Bioética: um grito por dignidade de viver. São Paulo: Paulinas, 2007.

Silva, E. G. Religiosidade e meio ambiente: das críticas dos ambientalistas à construção de uma ecoteologia. Revista Eletrônica Espaço Teológico, v. 4, n. 6, p. 132-140, 2010.

Vilhena, M. A. Ritos: expressões e propriedades - temas do ensino religioso. São Paulo: Paulinas, 2005.

Wainer, A. H. Legislação ambiental brasileira: subsídios para a história do direito ambiental. Rio de Janeiro: Revista Forense, 1999. 